\title{
Camel Party Zone, passive smoking, pesticide residues, and other pot-pourri
}

\author{
Web Watch is prepared by fack Cannon. Send correspondence to him by email \\ (jcannon@gate.net) (see page 81).
}

This issue of Tobacco Control marks the debut of the Web Watch column. Web Watch will follow issues relevant to tobacco control on the World Wide Web. The emphasis will be on new sites or new features appearing on the Web, including relevant URLs and short descriptions of the material. A Web site is available featuring the URL links referenced in this column. That URL is:

<http://www.gate.net/ jcannon/webwatch/>.

\section{California Environmental Protection Agency (Cal-EPA)}

The California Environmental Protection Agency has released for public comment the most comprehensive review of environmental tobacco smoke (ETS) since the 1986 Surgeon General's report. The report consists of eight volumes and appears to be the most extensive survey of the detrimental effects of secondhand smoke ever produced. No original research is included but instead an analysis of scientific studies on the topic is given (see page 87).

Start with the executive summary: $<$ <ttp://www.calepa.cahwnet.gov/oehha/docs/ets/ execsum.htm $>$.

All information relevant to the bottom line is contained within the summary, which can be easily read and printed by the accessing browser. The title page, preface, authors and acknowledgements, and the table of contents $<$ http://www.calepa.cahwnet.gov/oehha/docs/ets/ leadtxt.htm>

can also be viewed onscreen. Ignore any references to <authors.htm>; that information is contained in <leadtxt.htm>. The full eight-volume set

$<$ http://www.calepa.cahwnet.gov/oehha/docs/ets/ ets-main.htm>

contains the specific details but accessing the complete set is not as convenient.

Those volumes plus relevant figures and the appendix are contained in 10 self-extracting zip files ( ${ }^{\star}$.exe), which cannot be viewed online. They must first be downloaded into a convenient directory and then extracted by executing each individual file. (Execute figures.exe by typing "figures" at the DOS prompt, then <enter>.) If an extraction error message occurs, try downloading the file again.

The extraction process produces a number of ${ }^{*}$.doc files in Microsoft Word 7.0 format. This is fine for users of MS Word 7.0, but these files cannot be read with most other word processors, including earlier versions of MS
Word. Don't dispair-Microsoft has provided a solution in the form of a freeware (no charge) program called "wordview"

$<$ http://www.microsoft.com/word/Internet/Viewer/ iv default.htm>

that will allow both viewing and printing of "doc" files but not editing. Simply download 9 the appropriate file for your system and follow the standard installation instructions. Word-

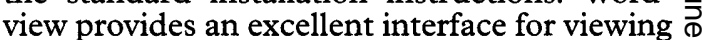
or printing the MS Word documents from the Cal-EPA.

Broin and Engle class-action lawsuits

Details of product liability lawsuits against the tobacco industry made an Internet appearance several months ago

<http://www.bottary.com/tobacco.htm>

following attorney Woody Wilner's victory on 9 August 1996, on behalf of plaintiff Grady Carter against Brown \& Williamson.

Recently Web sites covering the Broin and Engle class-action suits were opened by attorney Stanley Rosenblatt before the trials actually started. These sites were opened in part to comply with a judicial order regarding class notification.

The Broin class-action suit $<$ http://www. kinsella.com/broin/home.htm> was filed on behalf of all non-smoking airline flight attendants currently or previously employed by an airline based in the United States and who are suffering from a disease or disorder caused by exposure to secondhand smoke in airline cabins.

The Engle class-action suit <http://www.kinsella.com/engle/home.htm> was filed against tobacco companies on behalf $\tilde{N}$ of Florida smokers and survivors of smokers $\omega$ who have or had a medical condition or disease 2 caused by addiction to cigarettes that contain 0 nicotine.

Pesticide residues in tobacco products

Bill Drake's Smoke \& Illusion site

$<$ http://rampages.onramp.net/ bdrake/>

explores the relationship between pesticide residues in tobacco products and the health consequences of tobacco product use and 8 exposure.

He explores: (a) the factual basis for concern over the public health impact of pesticide con- $?$ tamination of cigarettes and other tobacco products; (b) what pesticides are in every puff taken, or every whiff of secondhand smoke inhaled; (c) what the tobacco companies did when their first generation poisons such as 
DDT, endrin, and dieldrin stopped killing everything in the fields due to insect resistance; and (d) cigarette manufacturers' use of synthetic smoking materials made from industrial waste, and/or reprocessed tobacco made from mill scrap and waste from their Third World operations.

$\mathrm{He}$ also proposes

$<$ http://rampages.onramp.net/ bdrake/ epafood.html>

that EPA is required by existing law to inspect tobacco products for pesticide contamination, as part of the US Environmental Protection Agency's duty to establish safe tolerance limits for residues of registered pesticides in food products.

The site is also dedicated to offering alternatives and solutions, including some high potential economic development possibilities for rural America and the Third World involving a new way to look at tobacco-as a biomass energy resource.

\section{Philip Morris front group exposed}

Numerous tobacco industry confidential documents have been on the Web for quite some time from the Brown \& Williamson collection

<http://www.library.ucsf.edu/tobacco/> and from Tobacco Industry Information <http://www.gate.net/ jcannon/tobacco.html>.

Now Parascope offers additional tobacco industry documents in conjunction with its Dossier project

<http://www.parascope.com/articles/0297/

smoke.htm>

report on the case of Contributions Watch, a recently exposed Philip Morris front group, whose staff of public relations professionals and political consultants masqueraded as a "public interest" group. An online archive of materials on the political scandal is presented that unravels the sophisticated scam and presents key memos produced by these staff and consultants.

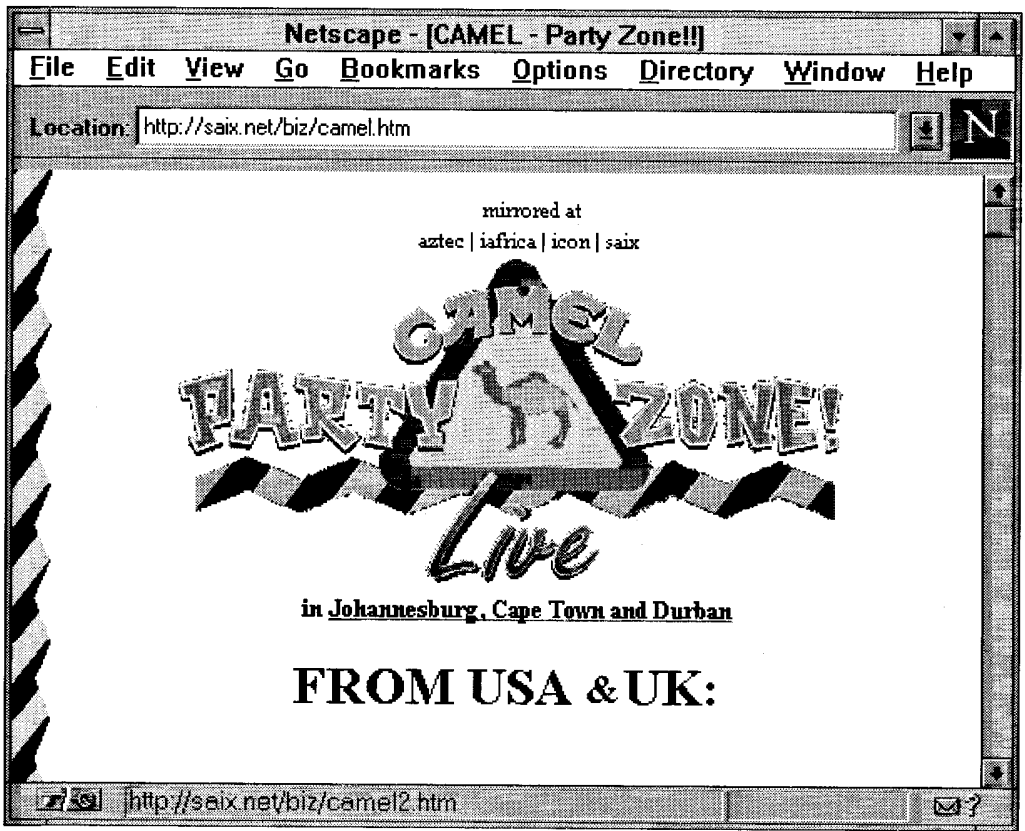

Web site for the Camel Party Zone, operated out of South Africa.

\section{Newslinks}

News articles are covered by copyright law, which precludes distribution outside the "fair use" provisions of the law.

Consequently it is not possible to provide a collection of such articles and post them on the World Wide Web without violating the law. However, it is possible and perfectly legal to provide a collection of links to such articles of common interest. When such an article is accessed it is transmitted via a link from the originating organisation instead of a mirror site.

\section{Gene Borio's Tobacco BBS}

$<$ http://www.tobacco.org/>

provides a comprehensive collection of links to news articles relevant to tobacco control. The links are updated daily, assuring current information.

Marc Gottlieb also provides an additional source of news links

<http://stic.neu.edu/News/newslinks.html>

from the State Tobacco Information Center.

\section{Tobacco industry Web sites}

Philip Morris (PM) opened a site $<$ ttp://pminfo.yrams.nl/>

several months ago for the purpose of publicising its misleading messages on the hazards of environmental tobacco smoke (ETS) exposure. It features graphical representations of the PM European advertising campaign

<http://pminfo.yrams.nl/301.htm>

comparing the risks of tobacco smoke exposure to those of drinking milk and eating biscuits.

Now both RJ Reynolds and Brown \& Williamson have opened Web sites. Unlike the Philip Morris site, their sites are designed to appeal to the younger generation.

Brown \& Williamson's site

$<$ http://www.circuitbreak.com/>

is believed to be the first US Web site for a cigarette brand.

Newspaper advertisements for Lucky Strike filters, running in the San Francisco area, ask readers to "Visit Lucky Strike's Circuit Breaker at http://www.circuitbreak.com".

Neither the tobacco company nor the brand, Lucky Strike, is mentioned anywhere on the site. Site visitors are requested to provide name, address, age, and smoking status. No indication is given that the information is being provided to a tobacco company. Claims have been made that site visitors answering "Yes" to the smoker question are mailed a teeshirt bearing the Lucky Strike logo or the Circuit Breaker name.

According to a Brown \& Williamson spokesman, "It's a lifestyle site and is a guide to clubs and other social activities in the Bay area. It's part of our test to see if it's a possible way to reach our male audience."

The Camel Party Zone

$<$ http://saix.net/biz/camel.htm>

operates out of South Africa. It promotes four top international dance acts-740 BOYZ, PIZZAMAN, CLOCK, and GILIETTE as well as three of the UK's hottest club DJs. It is billed as the ultimate non-stop dance party appearing in various South African cities. 
Claims are made that for the first time the South African public will get blasted into the international dance culture. Camel Promotions Manager, Sue Prinsloo, claims that they "have been working on this project for over two years" and they "are really thrilled about this event". The Camel logo is featured prominently throughout the site (figure).

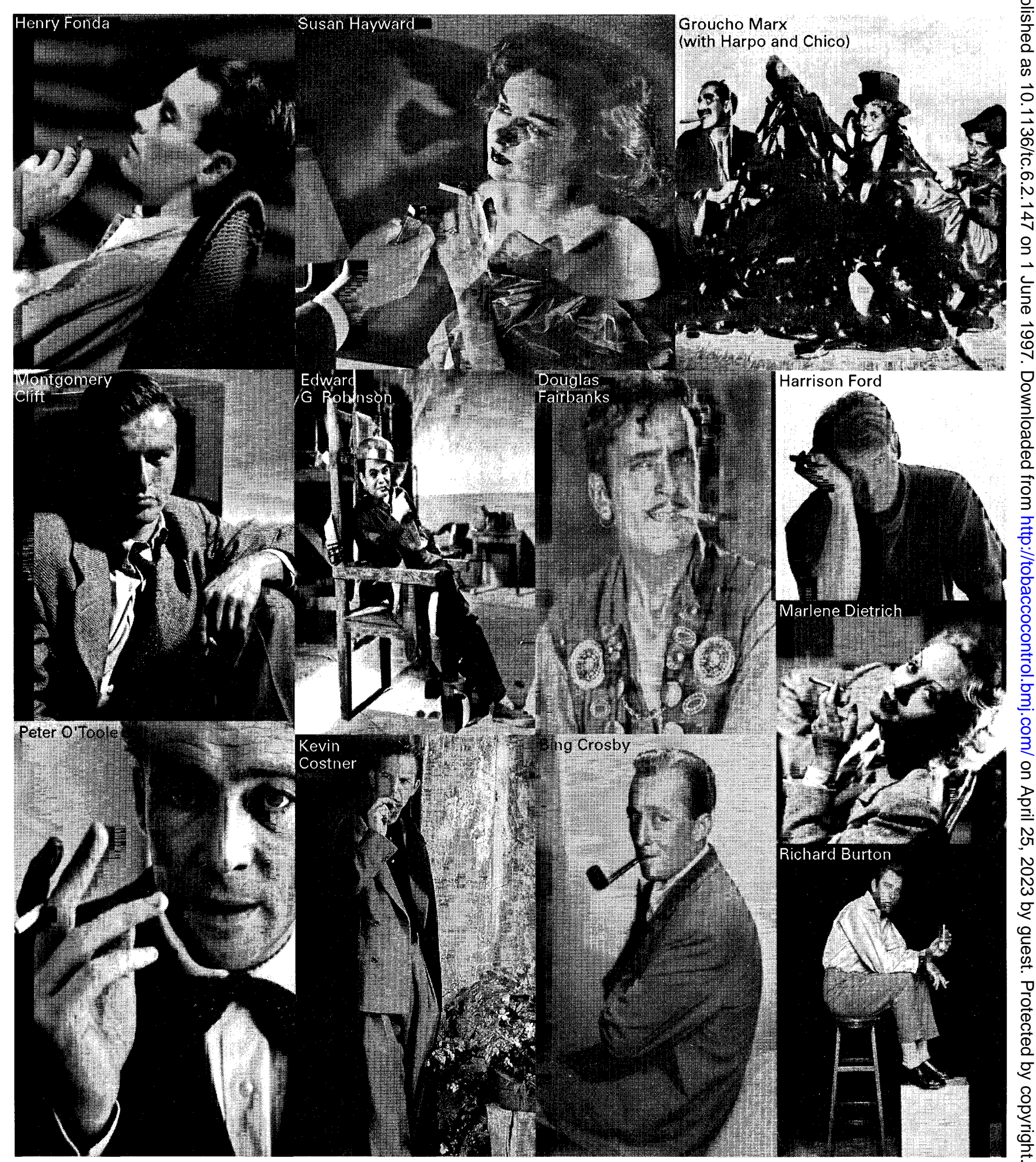

Smokes in the movies. Entertainment Weekly issued a "Special Collector's Issue" last autumn, in which it profiled "The 100 greatest movie stars of all time". Twelve of the 100 were shown smoking a cigar (Harrison Ford, Groucho Marx), a pipe (Bing Crosby, Edward G Robinson), or a cigarette (Richard Burton, Montgomery Clift, Kevin Costner, Marlene Dietrich, Douglas Fairbanks Sr, Henry Fonda, Susan Hayward, and Peter O'Toole). The issue also carried three, full-page cigarette advertisements. 